\title{
Probabilistic seismic hazard assessment in Greece - Part 2: Acceleration response spectra and elastic input energy spectra
}

\author{
G-A. Tselentis, L. Danciu, and E. Sokos \\ University of Patras, Seismological Lab, Rio 265 00, Patras, Greece
}

Received: 5 November 2009 - Revised: 8 December 2009 - Accepted: 9 December 2009 - Published: 12 January 2010

\begin{abstract}
This second part of the study, deals with the evaluation of the earthquake hazard in Greece in terms of the response spectral acceleration and the elastic input energy equivalent velocity. Four sets of predictive equations were selected, two for each type of spectra. Probabilistic hazard maps were created by determining the seismic hazard at grid points covering the region of interest. The maps are presented for the dominant periods of $0.2 \mathrm{~s}$ and $1.0 \mathrm{~s}$ for each spectrum. Uniform hazard response spectra (UHRS) for six cities located in the regions of highest estimated hazard are also presented. The comparison with elastic design spectra proposed by the latest national building code, has shown that the UHRS values exceed the design values at almost all periods.
\end{abstract}

\section{Introduction}

Seismic hazard evaluation, either deterministic or probabilistic, represents the most important tool to provide design engineers and planners with critical information about the earthquake prone areas. Such information may form a basis for effective mitigation strategies, including designing and constructing facilities to withstand earthquake shaking with limited damage, adequate land use and urban development, emergency response planning, etc. The current trend in the earthquake hazard evaluation calls for a proper prediction of effects from earthquakes whose damageability is defined by ground motion parameters. Therefore, seismic hazard evaluation requires selecting one or more ground motion parameters representative of the damage potential of the earthquake ground motion.

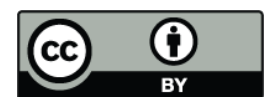

Correspondence to: G-A. Tselentis (tselenti@upatras.gr)
Traditionally, peak ground acceleration (PGA) and response spectra acceleration (SA) are the most commonly used parameters. However, both have significant shortcomings: PGA is purely related to the ground motion, and represents only the information of a maximum observed amplitude value; whereas SA is directly related to the characteristics of the structure (frequency and damping) interacting with the ground motion and does not account for the duration or the cyclic loadings of the ground motion. In this respect, elastic input energy spectra $\left(E_{\mathrm{i}}\right)$ might represent an alternative, because by combining the amplitude and duration of ground motion provides additional information to address the elastic response spectra drawbacks (Uang and Bertero, 1988).

In the framework of earthquake-resistant design, the importance of $E_{\mathrm{i}}$ have been long time recognized and many attempts have been done to develop the so-called energy-based seismic design methods (Benavent-Climent et al., 2002; Chai and Fajfar, 2000; Decanini and Mollaioli, 1998; Housner, 1956; Uang and Bertero, 1988). These studies emphasized that there is not a general established energy-based seismic design method yet; but they all pinpointed the use of duration and energy parameters to describe the reliable design earthquake, as they adequately capture the destructive potential of the different type of time histories (impulsive, nonimpulsive, periodic with long-duration pulses, etc.) corresponding to an earthquake. Although, the current trend in earthquake-resistant design relies upon Probabilistic Seismic Hazard (PSHA), the incorporation of energy-based spectra might provide an improved means for selecting earthquake scenarios and establishing design earthquakes for many types of engineering analyses (Chapman, 1999).

In this respect we have selected both acceleration- and energy-based spectra to characterize the seismic hazard in Greece. The seismic hazard is evaluated in a probabilistic manner and the spatial variations in the hazard will be illustrated through seismic hazard maps in terms of selected spectra, at periods of 0.2 and $1.0 \mathrm{~s}$. The obtained hazard maps

Published by Copernicus Publications on behalf of the European Geosciences Union. 
indicate different aspects of seismic hazards which arise from the seismotectonic characteristics of Greece. Because PSHA is site specific rather than regional, uniform hazard response spectra (UHRS) were computed and examined in detail for six municipalities located in the high seismic prone regions. All the reported results in the present study are for rock soil and $5 \%$ of damping and estimated for a $10 \%$ probability of exceedance in 50 years (0.002105 per annum).

From the point of seismic hazard assessment in Greece in terms of spectral values, the study of Theodulidis and $\mathrm{Pa}$ pazachos (1994b) represents the only attempt. They used the response spectra acceleration as a hazard parameter and proposed a $5 \%$ damped uniform hazard acceleration response spectra for 11 Greek cities computed for 475 years return period. In addition they have investigated the spectral acceleration amplification factors based on rock and alluvium soil conditions, and they observed a dependence of the spectra on distance, for a given type of soil. However, their study was based on a limited data set.

\section{Elastic input energy spectra}

According to Uang and Bertero (1990), the total absolute energy at any instant of time is given by:

$$
E_{\mathrm{i}}=E_{\mathrm{K}}+E_{\mathrm{S}}+E_{\zeta}+E_{\mathrm{H}}
$$

where $E_{\mathrm{K}}$ is the absolute kinetic energy, $E_{\mathrm{S}}$ is the strain energy, $E_{\zeta}$ is the absorbed viscous damping energy, and $E_{\mathrm{H}}$ is the hysteretic energy absorbed by the structure, which can be found by numerically integrating the nonlinear forcedisplacement history over the duration of the event. $E_{\mathrm{i}}$ is related to the total force applied at the base of a structure which physically, represents the inertial force equals the sum of the damping and restoring force. The elastic input energy can be converted to an equivalent velocity, by

$\mathrm{VE}_{\mathrm{i}}(T)=\sqrt{\left(2 E_{\mathrm{i}}(T) / m\right)}$

which in turn can be converted into an equivalent acceleration by

$\operatorname{AE}_{\mathrm{i}}(T)=\omega \operatorname{VE}_{\mathrm{i}}(T)=(2 \phi / T) \sqrt{\left(2 E_{\mathrm{i}}(T) / m\right)}$,

where $\omega$ is the circular frequency of motion and $T$ is the period. For the present investigation, we have selected to represent the hazard in terms of the acceleration-related parameter $\mathrm{SA}(T)$ and the elastic input energy equivalent velocity $\operatorname{VE}_{\mathrm{i}}(T)$.

\section{PSHA model}

In this study a probabilistic approach, originally developed by Cornell (1968) and extended later to incorporate the uncertainty of ground motion by Esteva (1970) was used to calculate seismic hazard values in Greece. The PSHA process involves an integration of the potential earthquake shaking from all possible source locations and magnitudes for some area around a site to calculate the probabilities of various levels of ground shaking at the site. The main elements in seismic hazard analysis comprises a set of seismotectonic source zones developed from a seismotectonic model of the study region; magnitude-recurrence relations for each of these zones; functional relations for the magnitude and distance dependence of the selected strong-motion parameters; and an analytical technique for computation of the ground motion parameters at the selected points throughout the region at desired probabilities of exceedance (Tselentis and Danciu, 2010a).

In order to estimate the probability of ground motion on a regional scale, earthquakes within a seismic source are typically assumed to occur randomly over time unless the historical or geological record indicates nonrandom occurrence (Thenhaus and Campbell, 2003). Therefore, assuming that the temporal occurrence of the earthquake follows a Poisson process, for any given level of ground shaking over a specified exposure period, the probabilistic method gives the chances of experiencing or exceeding that level of ground shaking over a specified exposure period. This assumption of Poisson process cannot be adopted in other type of studies, e.g., when calculating the probability of a prediction based for example on seismic electric signals to become successful by chance (Varotsos et al., 1996). The standard PSHA output is the seismic hazard curve, which is defined as:

$P\left(Y>y^{*} ; t\right)=1-\prod_{k}\left\{1-P_{k}(Y>y * ; t)_{k}\right\}$

where $P\left(Y>y^{*} ; t\right)$ is the exceedance probability due to all sources within time $t ; P_{k}$ is the exceedance probability due to the $\mathrm{k}$-th source, and $\prod$ is the series product.

When spectral values are employed as hazard parameters, Eq. (4) is solved over the range of all spectral periods. However, if a unique probability is assigned to the estimated spectra at each discrete period, equal probability spectra can be derived and referred to as a uniform hazard response spectrum (UHRS).

The seismogenic model used in the present study was well defined in the first part of this study (Tselentis and Danciu, 2010a). In summary, the model relies on the 67 seismogenic source zones proposed by Papaioannou and Papazachos (2000) and their seismicity parameters derived from the Greek catalogue thought to be complete for moment magnitudes $M \geq 8.0$ since $550 \mathrm{BC}$, for $M \geq 7.3$ since $1501, M \geq 6.0$ since $1845, M \geq 5.0$ since $1911, M \geq 4.5$ since $1950, M \geq 4.3$ since 1964 , and $M \geq 4.0$ since 1981 .

For each seismic source zone, the estimated mean occurrence rate per year, slope of the magnitude-frequency relationship and of the maximum observed magnitude were retained from the same study. The magnitude was restricted to the range $5 \leq M \leq M_{\max }$, where the upper bound magnitude 
$M_{\max }$ was defined as the maximum magnitude observed in each seismic source zone plus a 0.5 magnitude unit. The uncertainty associated with the maximum observed magnitude was estimated as 0.1 due to lack of information about the expected faults.

The dominant fault mechanism for each individual seismic source zone was identified and assigned to all the grid points within the zone. The spatial distribution of the Greek catalogue within the selected seismic source zones, together with the associated fault mechanism is presented in Fig. 1 of Part 1 of this investigation (Tselentis and Danciu, 2010a). A focal depth of $10 \mathrm{~km}$ was adopted for all seismogenic source zones.

The selection of the ground motion predictive models is important, because these must have a similar functional form, be homogeneous in terms of magnitude and use the same definitions for distance, soil category and fault mechanism. For the region of Greece, predictive equations for spectral values were first proposed by Theodulidis and Papazachos (1994a) and recently by Danciu and Tselentis (2007). The latest study proposed a set of predictive equations for response acceleration spectra and elastic input energy spectra and therefore represents the suitable candidate to estimate the SA and $\mathrm{VE}_{\mathrm{i}}$. The predictive model proposed by Danciu and Tselentis (2007), hereinafter called DT07, was derived from a dataset consisting of time-histories recorded on the last decades in Greece and therefore can be considered reliable for the purpose of the present investigation.

Theodulidis and Papazachos (1994), obtained a set of predictive equations for pseudo-velocity spectra based on 105 horizontal components of pseudo-velocity spectra from 36 earthquakes in Greece with surface wave magnitude $4.5<M_{\mathrm{S}}<7.0$ and 16 components from four earthquakes in Japan and Alaska with moment magnitude $7.0<M<7.5$ values in terms of earthquake magnitude, epicentral distance and geologic site conditions. Although, the study is very important, we did not consider this regression model in the present study, due to the abnormal large values observed particularly in the short period of the elastic velocity spectra on firm soil. This behavior was observed also by other authors (Burton et al., 2003).

Recently, Ambraseys et al. (2005), in the following AM05, have derived a set of ground motion predictive equations based on a set of 595 strong motion records recorded in Europe and Middle East. The contribution of the strong motion data recorded in Greece to the final database consisted of 112 records, approximately $22 \%$ from the total number of records. The functional form of the AM05 model takes into account the effect of the local soil effects and style-of-fault mechanism on the observed ground motions. The predictive model is valid for $M>5$ and distance to the surface projection of the fault less than $100 \mathrm{~km}$. It has to be pointed out that the AM05 predictive model considers the two definitions of the source-to-site distance: the distance to the surface projection of the fault, $R_{\mathrm{JB}}$, (also, known as the Joyner-Boore distance) for $M>6$ and the epicentral distance, $R_{\mathrm{E}}$, for small earthquakes for which the location of the causative fault has not been reported, mainly $M<6$.

Considering the predictive model for $\mathrm{VE}_{\mathrm{i}}$, additionally to the DT07 equations we have selected the predictive equations proposed by Chapman (1999), in the following CH99. The CH99 regression model for estimating the $\mathrm{VE}_{\mathrm{i}}$ was established using a dataset consisting of 303 records from 23 earthquakes in western North America. The CH99 regression model is homogenous in term of magnitude, $5.2 \leq M \leq 7.7$, and uses the nearest surface projection of the fault rupture as a source-to-site distance definition. As we have mentioned before, the candidate predictive models have to be uniform in terms of magnitude, distance definition and local soil conditions. In this respect, the models of AM05 and $\mathrm{CH} 99$ have to be uniform in terms of epicentral distance. Because for small earthquakes, $R_{\mathrm{JB}}$ and $R_{\mathrm{E}}$ are similar due to the small rupture planes of such earthquakes, the distance required in the AM05 model is corrected only for large earthquakes, with $M>6$. We have selected the conversion relationships proposed by Montaldo et al. (2005) based on the European data:

$R_{\mathrm{JB}}=0.8845 \mathrm{R}_{\mathrm{E}}-3.5525$

Unfortunately, it was not possible to empirically relate the nearest surface projection to the fault rupture with the epicentral distance. We have made a very rough approximation that for small events these two source-to-site distance definitions are equal and we expect that for events of $M>6$ the ground motion is underestimated. Because of these empirical conversions we expect that additional bias was introduced in the PSHA, and therefore we have decided to focus on the DT07 regression models and to give smaller weights to the other ground motion predictive models, including AM05, and $\mathrm{CH} 99$. Thus, the model DT07 for SA and $\mathrm{VE}_{\mathrm{i}}$ was assigned with a probability of 55\%, while AM05 and CH99 models were assigned with an equally probability of $45 \%$ each.

The uncertainty in the regression models (due to the scatter in the data from which was derived) is assumed to follow a log normal distribution. This assumption provides a means of quantifying the probability that given the occurrence of an earthquake of magnitude $M$ at a source-to-site distance $R$, the ground motion is above (or bellow) a ground motion level of interest. The exclusion of this uncertainty in the analysis would produce lower values on the PSHA results (Bender, 1984; Bommer and Abrahamson, 2006). Generally, the uncertainty of ground motion can be modelled using a lognormal distribution. Following the current PSHA practice we have directly incorporated the standard deviation into the PSHA calculation, and we have imposed cut-off limits of median plus and minus three standard deviations, to the "right-tail" of the lognormal distribution which tend to reach infinity. 


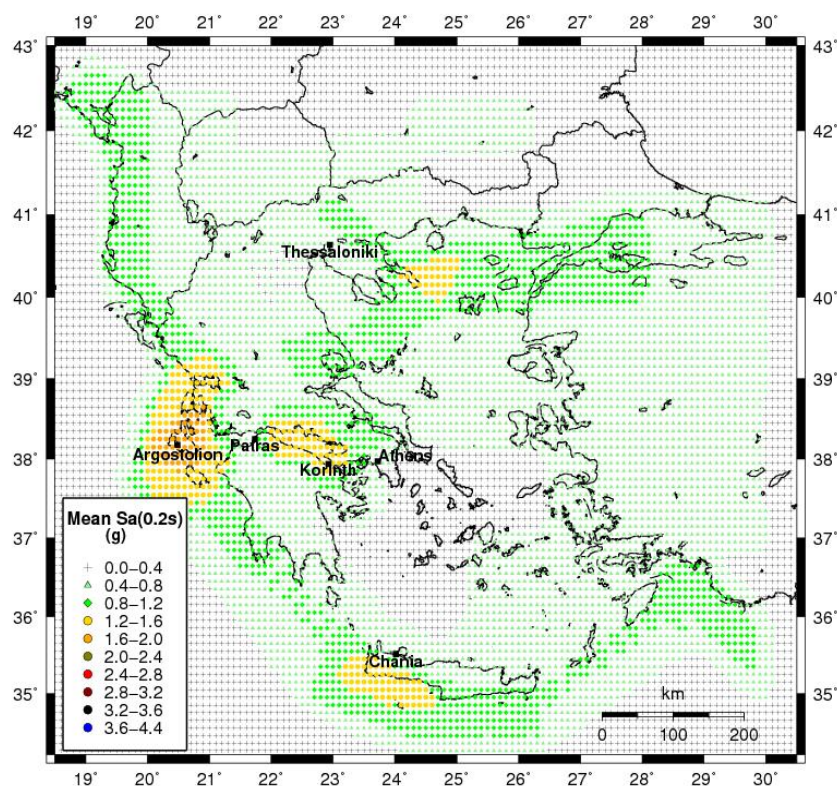

(a)

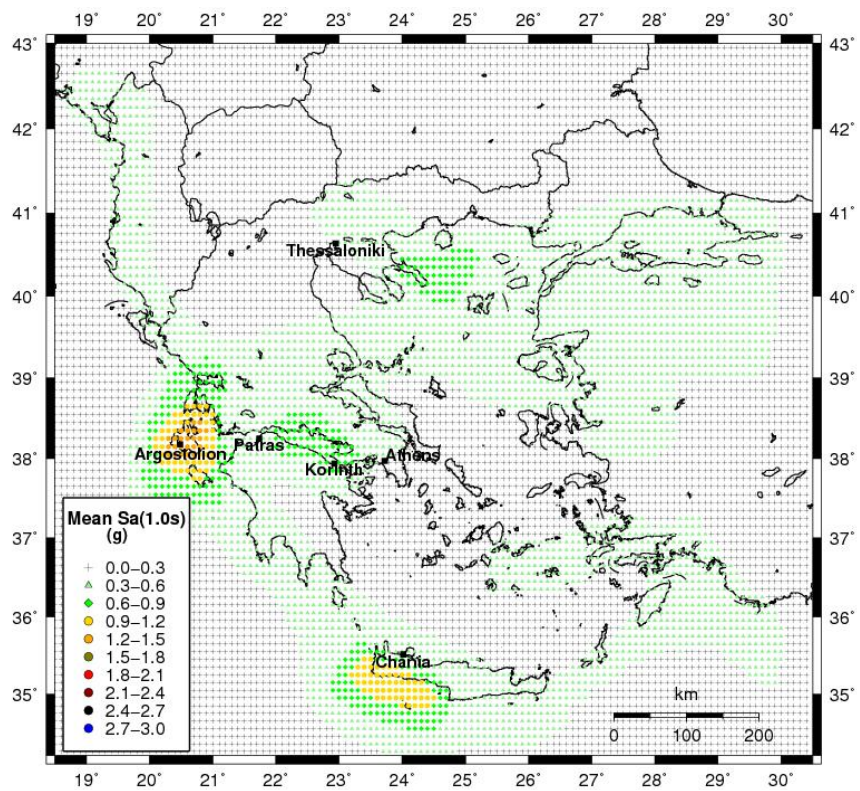

(b)

Fig. 1. (a) Probabilistic hazard maps in terms of $S A(0.2 s)$ corresponding to the mean values. (b) Probabilistic hazard maps in terms of $\mathrm{SA}(1.0 \mathrm{~s})$ corresponding to the mean values.

The functional form and the coefficients of the selected regression models are presented in Table 1 of Part 1 of this investigation (Tselentis and Danciu, 2010a). In this approach, PSHA's are conducted for response spectral values covering the periods from $0.1 \mathrm{~s}$ to $2.5 \mathrm{~s}$ were carried out for SA and from $0.1 \mathrm{~s}$ to $2.0 \mathrm{~s}$ for $\mathrm{VE}_{\mathrm{i}}$. The hazard computation was carried using the computer package Crisis2003 (Ordaz et al., 2003). The software allows assigning different predictive equations to different seismic source zones and accommodates for various source-to-site distance definitions. It has to be mentioned, that the regression models were assigned to each one of the 67 seismic source zones considered herein according with the dominant fault mechanism. The geographical territory of Greece was divided into a mesh of points with an interval of $0.1^{\circ}$ (about $10 \mathrm{~km}$ ) in latitude and longitude. The seismic hazard was evaluated at each grid point and the results are presented in the next section.

\section{PSHA results}

The seismic hazard values were computed for the whole grid, at about 10800 sites, extending over Greece at the $10 \%$ in 50 year probability level ( $1 / 475$ or 0.002105 per annum). The results were estimated for a uniform firm rock with an average shear velocity of $760 \mathrm{~m} / \mathrm{s}$ in the top $30 \mathrm{~m}$ corresponding to soil types A in the Greek building code (EAK, 2003). The outputs of the present investigation were: a regional hazard evaluation specified by means of probabilistic hazard maps and site specific hazard estimation quantified by means of a uniform hazard response spectrum.
The seismic hazard maps were constructed with the aim of the GMT package (Wessel and Smith, 1998) in terms of mean $\mathrm{SA}$ and mean $\mathrm{VE}_{\mathrm{i}}$, at $0.2 \mathrm{~s}$ and $1 \mathrm{~s}$, are shown in Figs. 1a, b and $2 \mathrm{a}, \mathrm{b}$, respectively.

A brief inspection of these maps reveals the features of the seismic hazard in Greece. The most obvious feature is that the areas of highest hazard encompass the regions with high historic seismicity and particularly those places where repeated earthquake activity was localized. The first area of high estimated hazard level is the region of central Ionian Islands, in the Western Hellenic Arc. The second area of high hazard is located in the off-shore end of the Northern Aegean, at the intersection of two different tectonic regimes; the extension of the Aegean Arc and the North Anatolian Fault. This region is dominated by large magnitude events, such as the catastrophic earthquakes of 17 August and 12 November 1999 near Izmit and Duzce (Burton et al., 2003). Another region prone to high seismic hazard is the region of central Greece which includes the region of Corinth Gulf. The fourth zone where high seismic hazard was estimated is the South-Western part of the Island of Crete. The later, might be underestimated since intermediate depth earthquakes which dominate this region, were not taken into account given that only shallow events were considered herein.

Figure $1 \mathrm{a}$ and $\mathrm{b}$ portray the spatial distribution of the probabilistic values of $\mathrm{SA}(0.2 \mathrm{~s})$ and $\mathrm{SA}(1 \mathrm{~s})$, respectively. It can be observed that seismic hazard increases from $0.2 \mathrm{~s}$ to $1.0 \mathrm{~s}$. Maximum values were obtained for short periods $(0.2 \mathrm{~s})$ with a range between $0.08 \mathrm{~g}$ and $2.08 \mathrm{~g}$ for mean $\mathrm{SA}$, whereas for long period $(1 \mathrm{~s})$ mean SA range between 0.07 


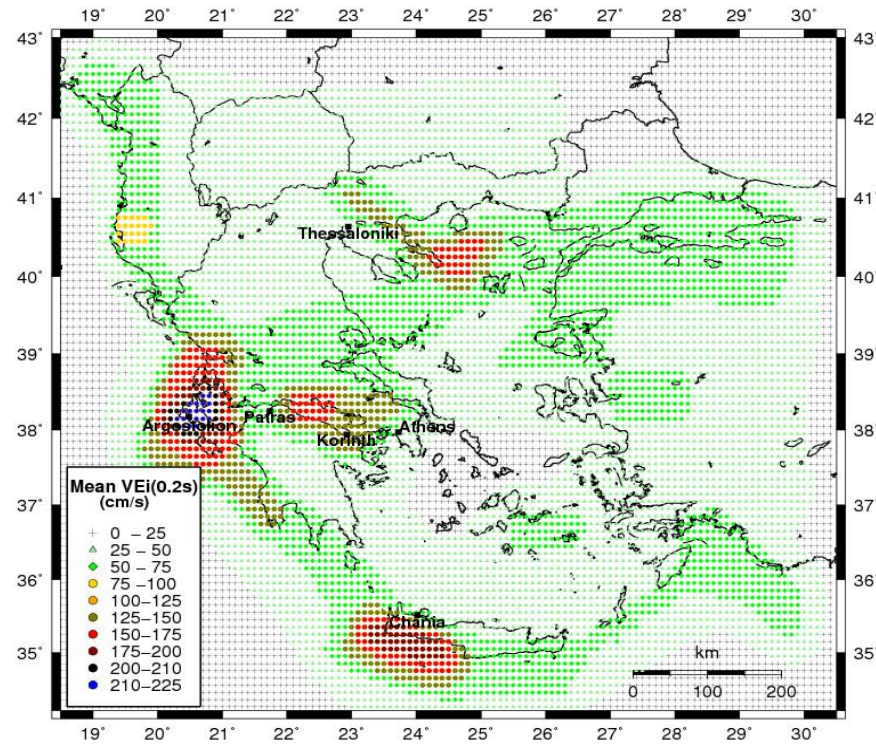

(a)

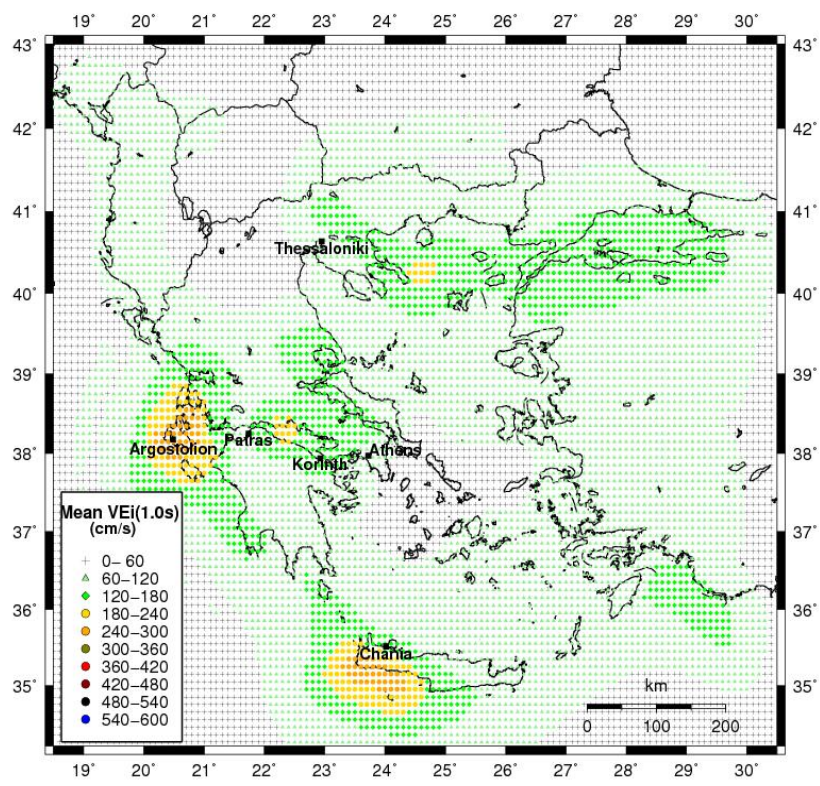

(b)

Fig. 2. (a) Probabilistic hazard maps in terms of $\operatorname{VE}_{\mathrm{i}}(0.2 \mathrm{~s})$ corresponding to the mean values. (b) Probabilistic hazard maps in terms of $\mathrm{VE}_{\mathrm{i}}(1.0 \mathrm{~s})$ corresponding to the mean values.

and $1.48 \mathrm{~g}$. Figure $2 \mathrm{a}$ and $\mathrm{b}$ illustrate the pattern of the seismic hazard quantified by $\operatorname{VE}_{\mathrm{i}}(0.2 \mathrm{~s})$ and $\mathrm{VE}_{\mathrm{i}}(1 \mathrm{~s})$ exceedance values. Comparing these energy-based hazard maps with those presented for spectra acceleration based hazard maps it can be pointed out that, the geographical distribution of the hazard exhibits a similar pattern, with minor differences in the Southern part of Crete, central region of Greece, around Corinth Gulf, and in the Northern Anatolian Fault.

The maximum hazard values decreases as the period increases from $0.2 \mathrm{~s}$ to $1.0 \mathrm{~s}$, and this different trend is due to the difference in the definition of the two spectra. Therefore, the hazard level described by $\operatorname{VE}_{\mathrm{i}}(0.2 \mathrm{~s})$ is smaller than the one estimated by $\mathrm{VE}_{\mathrm{i}}(1 \mathrm{~s})$. The maximum mean $\mathrm{VE}_{\mathrm{i}}(0.2 \mathrm{~s})$ values, about $130 \mathrm{~cm} / \mathrm{s}$ are reached in the Ionian Islands along the Western Hellenic arc, while the maximum mean $\mathrm{VE}_{\mathrm{i}}(1 \mathrm{~s})$ values are around $280 \mathrm{~cm} / \mathrm{s}$ for the same region. Moreover, the difference observed between the estimated $\mathrm{SA}(0.2 \mathrm{~s})$ and $\mathrm{SA}(1 \mathrm{~s})$ maps, as well as for $\mathrm{VE}_{\mathrm{i}}(0.2 \mathrm{~s})$ and $\mathrm{VE}_{\mathrm{i}}(1 \mathrm{~s})$ indicate that a single seismic hazard map for all periods may not be sufficient. It is worth mentioning, that for Greece, there are no previously proposed hazard maps in terms of spectral values, therefore no comparison can be made.

\section{Uniform Hazard Response Spectra (UHRS)}

A standard PSHA output is the uniform hazard response spectra (UHRS), which is a response spectrum having a uniform (or constant) probability of exceedance at the particular site. UHRS does not represent the effect of just one earthquake, but instead, will represent the envelope of the effects of earthquakes of varying magnitudes and source-to-site distances. It is customary to find that the short period part of the UHRS is governed by contribution from small-to-moderate earthquakes from nearby sources, whereas the larger magnitude earthquakes from distant sources affect the long period of the spectrum (range 0.5-2 s).

The UHRS is derived from hazard curves and these hazard curves are the components that combine the motions from different scenarios. Nonetheless it should be acknowledged that the UHRS assumes that spectral ordinates at different periods are statistically independent and it does not generally correspond to the spectrum of a specific earthquake scenario. In this respect a disaggregation of the PSHA is required (Bazzurro and Cornell, 1999). UHRS represent an appropriate probabilistic representation of the earthquake action and represents a key element of seismic design codes such as the National Building Code of Canadian (NBCC, 2005) or the International Building Code (IBC, 2000).

We have computed the UHRS for six cities located in the highest estimated seismic prone areas. These cities are: Athens, Thessaloniki, Patras, Korinthos, Argostolion, and Chania. The mean UHRS were obtained for a unique return period of 475 years and presented in Fig. 3a for SA and 

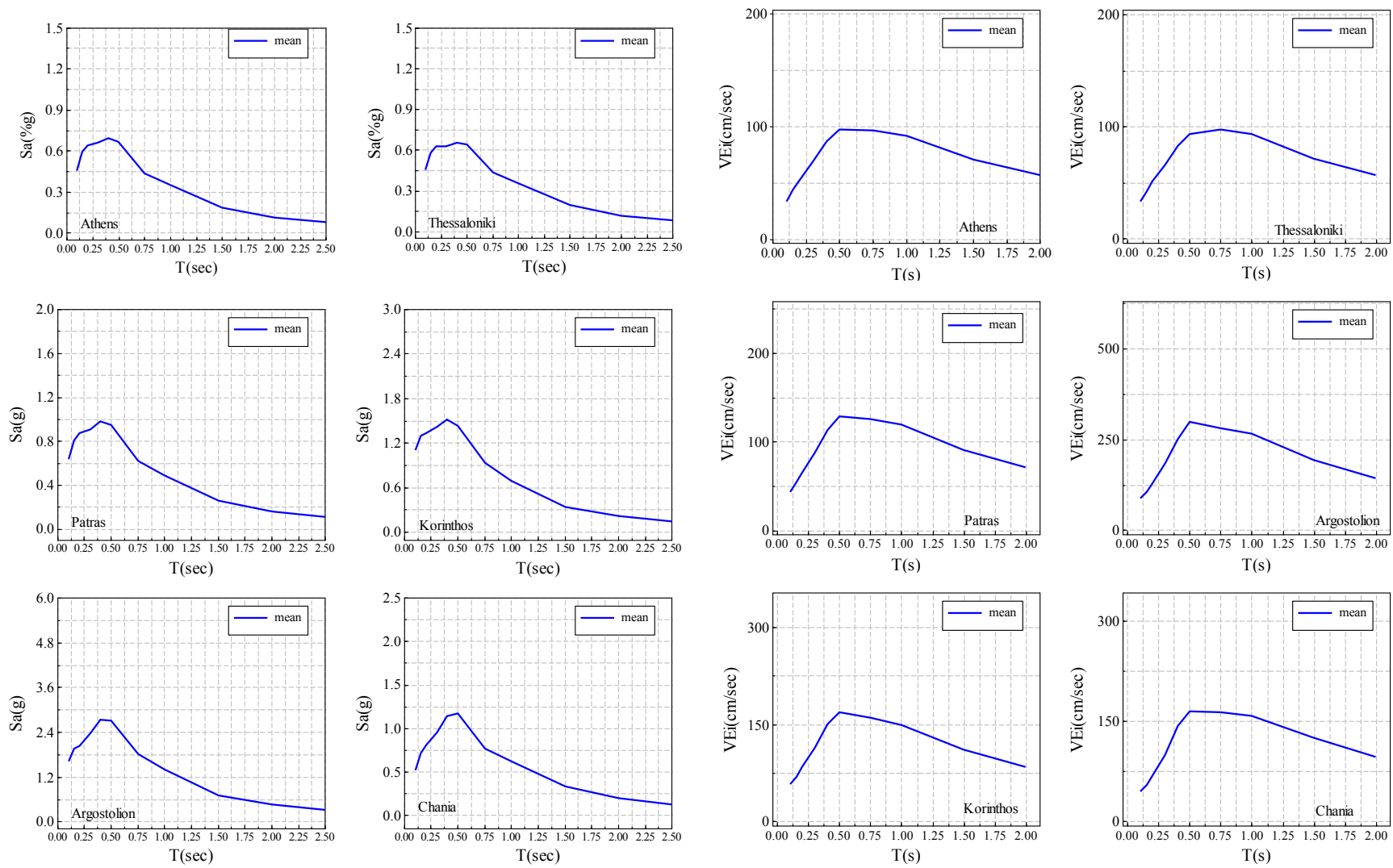

(a)

(b)

Fig. 3. (a) UHRS in terms of SA for the selected cities. (b) UHRS in terms of $\mathrm{VE}_{\mathrm{i}}$ for the selected cities.

in Fig. $3 b$ for $\mathrm{VE}_{\mathrm{i}}$, respectively. These graphs illustrate the high frequency content of both UHRS; with the picks lying on the range of $0.2 \mathrm{~s}$ to $0.4 \mathrm{~s}$ for $\mathrm{SA}$ (valid for all percentile) and on the range of $0.4 \mathrm{~s}$ to $0.75 \mathrm{~s}$ for $\mathrm{VE}_{\mathrm{i}}$. It is common to find that the large magnitude events affect the long period branch of a UHRS whereas small magnitude events affect the short-period branch. This indicates that UHRS in terms of SA is characterized in the short period by small-to moderate events and the UHRS in terms of $\mathrm{VE}_{\mathrm{i}}$ is dominated by large magnitude events at long-period region. Therefore if the hazard is assessed on the basis of $\mathrm{VE}_{\mathrm{i}}$, the hazard posed by larger magnitude earthquakes contributes more to the total hazard, than that based on SA.

It can be seen also, from Fig. 3a and $b$ that Argostolion and Korinthos have the highest hazard spectra of this set, Chania and Patras are about equal, and Thessaloniki and Athens are lower at all periods. Argostolion exhibits the highest level of estimated hazard, with a maximum value for mean SA of $2.95 \mathrm{~g}$ at $0.45 \mathrm{~s}$ and for $\mathrm{VE}_{\mathrm{i}}$ mean values of $300 \mathrm{~cm} / \mathrm{s}$ at $0.5 \mathrm{~s}$, thus the characteristic period for the city appears to be around $0.45-0.5 \mathrm{~s}$. This implies that the structures with a fundamental period of vibration around these characteristic periods are likely to be vulnerable.
The location of Argostolion is close with the epicenters of some major earthquakes occurred in Greece (Papazachos and Papazachou, 2002). The high estimated hazard on this area is also due to localization of repeated earthquake activity; this localization has a pronounced effect on the hazard calculations compared to areas where the seismicity, while high, is more diffuse and less repetitive. Since the site is located close to a high activity region, the hazard is dominated by the nearby events at both short and long spectral periods. Among the selected cities, Athens exhibits the smallest hazard, with maximum mean SA values estimated at about $0.7 \mathrm{~g}$ at $0.45 \mathrm{~s}$ and for mean $\mathrm{VE}_{\mathrm{i}}$ values of about $97.5 \mathrm{~cm} / \mathrm{s}$ at $0.5 \mathrm{~s}$ and $0.75 \mathrm{sec}$.

\section{Comparison of UHRS with the design codes}

Most seismic building codes, including the Greek seismic code (EAK, 2003) and the European seismic prevision (Ec8) rely on the concept of elastic ground acceleration response spectrum due to the traditional and almost universal use of the force-based seismic design approach. The elastic response spectrum is usually established by the scaling of a fixed spectral shape (adapted for local site classification) to 
a single ground motion parameter - PGA - deterministically or probabilistically estimated from the seismicity of the region. In general the shape of a spectrum is statistically derived from a collection of numerous spectra representative of the ground motions recorded in different earthquakes under similar conditions (especially characterized by local soil conditions).

Despite its widespread and acceptance as a convenient design tool, the use of normalized shape spectra has advantages in its simplicity; but not without criticism. In both seismic codes the spectral shape is considered completely independent from seismic hazard, only site conditions affect the spectral shape. It has been recognized, that spectral shape is also dependent upon earthquake magnitude and source-tosite distance, local site conditions and direction of fault rupture propagation, but conventional elastic design spectra does not take into account these effects. Moreover, the probabilities of exceedance of a normalized-shape design spectrum may be different over the entire frequency (or period) range of interest and cannot be considered as an uniform hazard spectrum (Kramer, 1996).

An attempt to consider the earthquake magnitude effect on the spectral shape dependence on the fixed spectral shape was proposed in Eurocode 8. The European seismic regulation introduced two types of design spectra for low (type II) and high (type I) seismic regions that depend on the maximum magnitude of earthquakes that are expected to affect the site. Both spectra rely in the value of the reference PGA, which is chosen by the National Authorities for each seismic zone, corresponding to the reference return period (475years) of the seismic action for the no-collapse requirement. In EAK (2003), the seismic hazard is defined by a PGA map estimated for 475-year return period, which depicts the region of Greece in three zones of homogenous hazard with the following seismic zone factors (PGA): $0.16 \mathrm{~g}$ for zone I; $0.24 \mathrm{~g}$ for zone II and $0.36 \mathrm{~g}$ for zone III.

It is interesting to note that, the first difference arise from the slightly different values of the corner periods introduced for the same type of soil categories. For rock soil condition (category A) the region of constant acceleration defined by $T_{\mathrm{B}}$ in EAK starts at $0.10 \mathrm{~s}$ while in Ec8 starts at $0.15 \mathrm{~s}$. However, another difference of the EAK (2003) from the Ec8 is in the exponential coefficient of the descending slope of the elastic response spectrum ( $2 / 3$ instead of 1$)$. Thus, the EAK elastic design spectra is more conservative in the moderate to long region of the spectra (velocity and displacement region of elastic spectra), exhibiting a descending slope larger than the one proposed by EC8.

Plots of the two elastic design spectra proposed by EAK (2003) and Ec8 (type I) together with UHRS estimated for the selected cities are plotted in Fig. 4. The elastic design spectra plotted in Fig. 4 corresponds to a region of high seismic zone, (reference PGA $=0.36 \mathrm{~g}$ ), estimated in bedrock (soil category A) and $5 \%$ damping. The UHRS in terms of SA computed for the selected cities were normalized with the

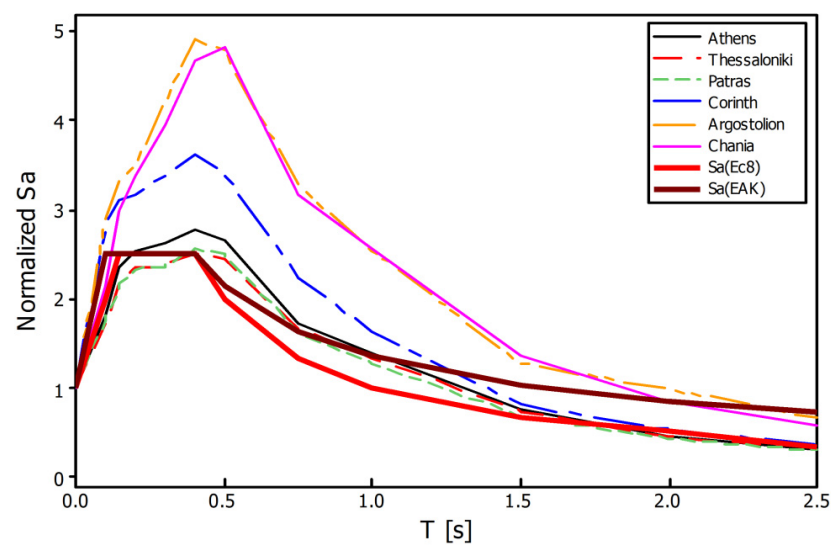

Fig. 4. Comparison of the normalized UHRS (SA) for the selected cities vs. the normalized elastic acceleration response spectra proposed by EAK (2003) and Ec8.

PGA computed in the first part of the study of Tselentis and Danciu (2010a).

Recalling the median PGA values, corresponding to a reference return period of 475 years and estimated for the selected cities we get: $0.24 \mathrm{~g}$ for Athens, $0.26 \mathrm{~g}$ for Thessaloniki, $0.36 \mathrm{~g}$ for Patras, $0.40 \mathrm{~g}$ for Corinth, $0.23 \mathrm{~g}$ for Chania, and $0.54 \mathrm{~g}$ for Argostolion. It can be noted that these scaling PGA values obtained for Thessaloniki, Patras, Corinth and Argostolion are exceeding the design values proposed by the reference hazard zonation proposed by EAK (2003). It is evident from Fig. 4 that UHRS in terms of SA are larger than those introduced for elastic design spectra, from both EAK (2003) and Ec8, at a predominant period of $0.4 \mathrm{~s}$.

The UHRS (SA) for Argostolion and Chania exhibits larger values over the entire region of the elastic design spectra; the same trend is noted for the UHRS (SA) estimated for Corinth, with larger values over the short to moderate region of the elastic design spectra upon $1.0 \mathrm{~s}-\mathrm{EAK} 2003$ and $1.5 \mathrm{~s}-$ Ec8. The UHRS(SA) for Athens, Patras and Thessaloniki are corroborative with the code spectra, with slightly larger values around the period bandwidth of $0.4 \mathrm{~s}$ to $0.75 \mathrm{~s}$ in the case of EAK2003 and $0.4 \mathrm{~s}$ to $1.5 \mathrm{~s}$ period in the case of Ec8.

A direct comparison between UHRS in terms of $\mathrm{VE}_{\mathrm{i}}$ and elastic response spectra is not possible because both regulations do not specify the seismic action in terms of elastic energy spectra. One attempt is to convert the $\mathrm{VE}_{\mathrm{i}}$ into an input energy related acceleration parameter $\left(\mathrm{AE}_{\mathrm{i}}\right)$ with the aim of Eq. (3) and to select an appropriate scaling factor to normalize the shape of the obtained UHRS. One suitable scaling parameter is the seismic hazard energy factor $-\left(f_{\mathrm{AEI}}\right)$ defined by Decanini and Mollaioli (1998) and Decanini et al. (1994) as the area enclosed by an $E_{\mathrm{i}}$ spectrum according to different interval of periods. The area used in scaling, and also adopted as the seismic hazard parameter, is that one enclosed by the energy spectrum in the intervals of periods 


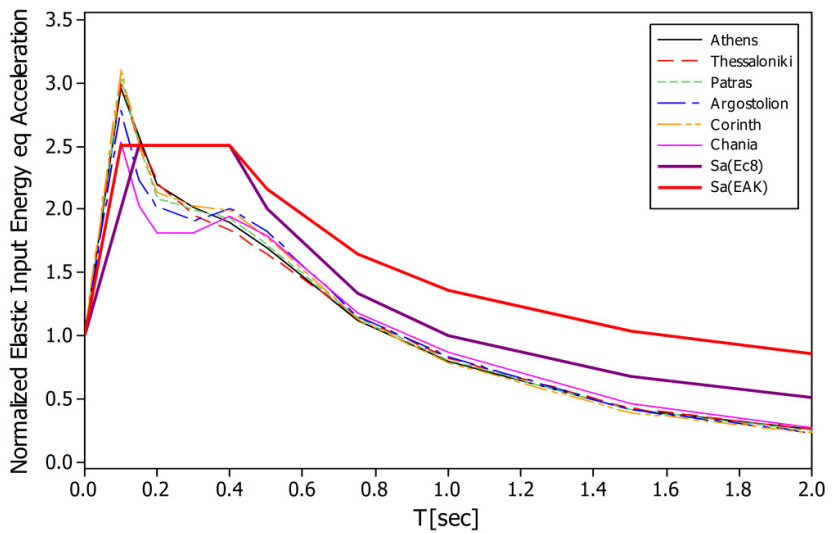

Fig. 5. Comparison of the normalized UHRS $\left(\mathrm{AE}_{\mathrm{i}}\right)$ for the selected cities vs. the normalized elastic acceleration response spectra proposed by EAK (2003) and Ec8.

between $0.05 \mathrm{~s}$ and $4 \mathrm{~s}, f_{\mathrm{AEI}}$, can be seen as an energy version of the Housner Intensity (Housner, 1952) with minor differences due to the fact that the pseudo-velocity spectrum represents the lower bound of the $E_{\mathrm{i}}$ spectrum.

Here, a slightly modified definition of the $f_{\text {AEI }}$ was used; the computation was carried out for the period interval $0.1 \mathrm{~s}$ to $2.0 \mathrm{~s}$ and the following values were obtained for the selected cities: $0.7 \mathrm{~g}$ for Athens, $0.695 \mathrm{~g}$ for Thessaloniki, $0.885 \mathrm{~g}$ for Patras, $1.164 \mathrm{~g}$ for Corinth, $1.991 \mathrm{~g}$ for Argostolion, and $1.124 \mathrm{~g}$ for Chania. The normalized UHRS ( $\left.\mathrm{AE}_{\mathrm{i}}\right)$ are plotted together with the elastic response spectra proposed by EAK (2003) and Ec8 on bedrock (soil category A) in Fig. 5. As can be seen, the normalized UHRS in terms of $\mathrm{AE}_{\mathrm{i}}$, reported for the selected cities are higher than the elastic response spectra proposed by regulations, particularly at short periods. The exception is the UHRS computed for the city of Chania, which is smaller than both elastic design spectra. The predominant period associated to the UHRS ( $\left.\mathrm{AE}_{\mathrm{i}}\right)$ is around $0.2 \mathrm{~s}$.

The higher values observed at the short period region of both UHRS (SA)and $\mathrm{AE}_{\mathrm{i}}$ might be explained by the fact that this part of the spectrum is characterized by small nearby earthquakes. A deaggregation analysis might be employed to estimate such a contribution to the final PSHA results (Tselentis and Danciu, 2010b). The higher $\mathrm{AE}_{\mathrm{i}}$ values observed in the short period range of the spectra might indicate that the one to two stories buildings are likely to be vulnerable to short period ground motion caused by these shallow earthquakes. The use of UHRS $\left(\mathrm{AE}_{\mathrm{i}}\right)$ might offer an advantage due to the fact that the former takes into account the duration of the time history acceleration. From the structural design point of view, if the equivalent static load approach is employed, both elastic response spectra and UHRS should be appropriate. If time histories are required for a dynamic analysis of irregular or high ductility structures then both spectra are inappropriate unless accompanied by an earthquake scenario or a controlling/design event.

\section{Conclusions}

The seismic hazard was assessed for Greece in terms of response spectra acceleration and elastic input energy. The study relies on the seismogenic zones proposed by Papaioannou and Papazachos (2000) and the seismic data are given in the Greek earthquakes catalogues. Four sets of predictive equations were selected, two for each type of spectra: DT07 and AM05 for SA and DT07 and CH99 for $\mathrm{VE}_{\mathrm{i}}$. The spectral exceedance values were computed with $10 \%$ probability of exceedance in 50 years in a uniform rock site condition. Probabilistic hazard maps were created by applying the PSHA approach to grid points covering the region of interest. The spatial distribution of the estimated spectral values illustrated four zones of high estimated hazard by all the spectra considered (i) Western Hellenic Arc, (ii) Central Greece, (iii) Northern Hellenic Arc, and (iv) South-Western Crete Island.

One of the major outcomes of the PSHA is the UHRS for six cities located in the regions of highest estimated hazard. Among the selected cities, including Athens, Thessaloniki, Patras, Korinthos, Chania, and Argostolion, the latest was found to pose the highest seismic hazard. The comparison with elastic design spectra proposed by EAK (2003) and Ec8 has shown that the UHRS values exceed the design values at almost all periods.

It should be emphasized that the probabilistic seismic hazard maps represent a statistical forecast; therefore it has its own limitations. One shortcoming is that it is based solely on the available seismogenic source zones. The seismic ground shaking hazard information developed in this study will contribute to the establishment of a regional seismic hazard framework from which seismologist, geologist, and engineers can benefit as a general guidelines and reference for multiple engineering solutions.

Edited by: M. E. Contadakis

Reviewed by: E. Lekkas and another anonymous referee

\section{References}

Ambraseys, N., Douglas, J., Sarma, S. K., and Smit, P. M.: Equations for the estimation of strong ground motion from shallow crustal earthquakes using data from Europe and the Middle-Est: horizontal peak ground acceleration and spectral acceleration, B. Earthq. Eng., 3, 1-53, 2005.

Bazzurro, P. and Cornell, A. C.: Dissagregation of Seismic Hazard, B. Seismol. Soc. Am., 89(2), 501-520, 1999.

Benavent-Climent, A., Pujades, L. G., and Lopez-Almansa, F.: Design energy input spectra for moderate-seismicity regions, Earthq. Eng. Struct. D., 31, 1151-1172, 2002.

Bender, B.: Incorporating acceleration variability into seismic hazard analysis, B. Seismol. Soc. Am., 74(2), 1451-1462, 1984.

Bommer, J. J. and Abrahamson, N. A.: Why Do Modern Probabilistic Seismic-Hazard Analyses Often Lead to Increased Hazard Estimates?, B. Seismol. Soc. Am., 96(4), 1967-1977, 2006. 
Bommer, J. J. and Abrahamson, N. A.: Why Do Modern Probabilistic Seismic-Hazard Analysis Often Lead to Increase Hazard Estimates?, B. Seismol. Soc. Am., 96(4), 1967-1977, 2006.

Burton, P. W., Yebang, X., Tselentis, G-A., Sokos, E., and Aspinall, W.: Strong ground accelaration seismic hazard in Greece and neighboring regions, Soil Dyn. Earthq. Eng., 23, 159-181, 2003.

CEN. Eurocode 8: Design of structures for earthquake resistance of structures - Part 1: General rules, seismic actions and rules for buildings, prEN 1998-1, Brussels, 2002b.

Chai, Y. H. and Fajfar, P.: A Procedure for Estimating Input Energy Spectra for Seismic Design, J. Earthq. Eng., 4(2), 539-561, 2000.

Chapman, M. C.: On the use of elastic input energy for seismic hazard analysis, Earthq. Spectra, 15(2), 607-635, 1999.

Cornell, C. A.: Engineering Seismic Risk Analysis, B. Seismol. Soc. Am., 58, 1583-1606, 1968.

Danciu, L. and Tselentis, G-A.: Engineering Ground-Motion Parameters Attenuation Relationships for Greece, B. Seismol. Soc. Am., 97(1B), 162-183, 2007.

Decanini, L. and Mollaioli, F.: Formulation of Elastic Earthquake Input Energy Spectra, Earthq. Eng. Struct. D., 27, 1503-1522, 1998.

Decanini, L., Mollaioli, F., and Oliveto, G.: Observations and lessons learned from the earthquake of 13th December 1990 in South-East Sicily, Proc. of the 10th European Conference on Earthquake Engineering, Balkema, Wien, 1935-1943, 1994.

EAK: Greek Seismic Code, edited by: Earthquake Planning \& Protection Organizatin. Athens - Greece, 72 pp., 7 appendixes, 2003 (in Greek).

Esteva, L.: Seismic Risk and Seismic Design Decisions, in: Seismic Design for Nuclear Power Plants, edited by: Hansen, R. J., Massachusetts Inst. of Tech. Press, Cambridge, MA, USA, 142-82, 1970.

Housner, G. W.: Intensity of ground motion during strong earthquake, California Institute of Technology, Pasadena, California, 1952.

Housner, G. W.: Limit design of structures to resist earthquakes, Proc. 1st. World Conference Earthquake Engineering, Berkeley, California, EERI, 1956.

Kramer, S. L.: Geotechnical Earthquake Engineering, Prentice Hall, 1996.

Montaldo, V., Faccioli, E., Zonno, G., Akinci, A., and Malagnini, L.: Treatment of ground-motion predictive relationships for the reference seismic hazard map of Italy, J. Seismol., 9, 295-316, 2005.
Ordaz, M., Aguilar, A., and Arboleda, J.: CRISIS2003, Ver. 3.1, Program for computing seismic hazard, Instituto de Ingeniería, UNAM, Mexico, 2003.

Papaioannou, C. A. and Papazachos, B. C.: Time-Independent and Time-Depended Seismic Hazard in Greece Based on Seismogenic Sources, B. Seismol. Soc. Am., 90, 22-33, 2000.

Papazachos, C. B. and Papazachou, K.: Earthquakes in Greece, Ziti Publications, Thessaloniki, 2002.

Thenhaus, P. C. and Campbell, K. W.: Seismic Hazard Analysis, in: Earthquake Engineering Handbook, edited by: Chen, W.-F. and Schawthorn, C., CRC Press, VIII1-50, 2003.

Theodulidis, N. P. and Papazachos, B. C.: Dependence of strong ground motion on magnitude-distance, site geology and macroseismic intensity for shallow earthquakes in Greece: II, Horizontal Pseudo-velocity, Soil Dyn. Earthq. Eng., 13, 317-343, 1994a.

Theodulidis, N. P. and Papazachos, B. C.: Seismic Hazard Assessment in Greece in terms of spectral values, Bull. Geol. Soc. Greece, XXX(3), 205-213, 1994b.

Tselentis, G-A. and Danciu, L.: Probabilistic seismic hazard assessment in Greece - Part 1: Engineering ground motion parameters, Nat. Hazards Earth Syst. Sci., 10, 25-39, 2010a, http://www.nat-hazards-earth-syst-sci.net/10/25/2010/.

Tselentis, G-A. and Danciu, L.: Probabilistic seismic hazard assessment in Greece - Part 3: Deaggregation, Nat. Hazards Earth Syst. Sci., 10, 51-59, 2010b, http://www.nat-hazards-earth-syst-sci.net/10/51/2010/.

Uang, C. M. and Bertero, V. V.: Implications of recorded earthquake ground motions on seismic design of building structures, Earthquake Engineering Research Center, Berkeley, CA, Report No. UCB/EERC-88/13, 1988.

Uang, C. M. and Bertero, V. V.: Evaluation of seismic energy in structures, Earthq. Eng. Struct. D., 19, 77-90, 1990.

Varotsos, P., Eftaxias, K., Lazaridou, M., Antonopoulos, G., Makris, J., and Poliyannakis, J.: Summary of the five principles suggested by P. Varotsos et al. (1996) and the additional questions raised in this debate, Geophys. Res. Lett., 23, 1449-1452, 1996.

Wessel, P. and Smith, W. H. F.: Free software helps map and display data, EOS T. Am. Geophys. Un., 72, 444-446, 1998. 